\title{
Discussion: Multi-criteria contractor selection - a practical application of analytic hierarchy process
}

\section{Adebayo Oladapo MSc, PhD}

Senior Lecturer, School of Built \& Natural Environment, University of Central Lancashire, Preston, UK
Richard Patterson BA, MBA, CEng, MICE

Procurement and NEC Specialist, Mott MacDonald, Cambridge, UK

\section{Contribution by R. Patterson}

For an engineer specialising in procurement this paper (Oladapo, 2011) was an interesting read and reminder of maths courses from long ago. The matrix analysis was a blast from the past, but all clearly explained.

The paper and its readers could perhaps have benefited from a little more discussion of the interface with reality as suggested in the following items.

(a) It should be noted that, for significant projects, bid selection should follow a prequalification stage.

(b) Certain criteria, such as 'years in business' are often included in the prequalification criteria and, if so, are precluded by much procurement legislation from being considered again in bid evaluation.

(c) Most bid selection processes have to rely exclusively on submitted information only and so in Section 3.1, the sentence 'they also used their knowledge of the contractors' past performances and scored them ...' is a little dangerous.

(d) It is common, and often appropriate to include as criteria the minimum scores on some of the key quality criteria.

(e) It would have been useful to refer to Ciria's publication Selecting by Value (Ciria, 1998). This seminal document is being updated but still provides excellent guidance to practitioners.

The use of the pair-wise comparisons to help a team develop weighting criteria was of interest. Can the author direct readers to software tools designed to aid this process?

\section{Author's reply}

I find the contributor's comments very pertinent and encouraging for the following reasons.

(a) The observation that, for significant projects, bid selection should include a prequalification stage which uses the 'contractors' years in business' as one of the criteria is indeed the ideal which unfortunately is not universally upheld. This is especially the case in both the private and public sectors of the country where the study was carried out.

(b) Again, I agree with the contributor that the bid selection process must rely exclusively on information supplied by bidders; but in this particular exercise, tenders were invited from a standing list of contractors who had at various times in the past worked with the client and/or his professional advisers. The advisers thought it appropriate to rate the contractors by their past performances as well to balance the contractors' self-declared information.

The purpose of the matrix algebra displayed in the article was to establish the theoretical foundation of the use of the analytic hierarchy process (AHP). In practice, this is tedious and can be avoided using very simple, user-friendly AHP software, many of which are now freely available on the internet. One of them is provided by Conseilleurs en Gestion et Informatique (CGI) and is available at http://www.isc.senshu-u.ac.jp/ $\sim$ thc0456/EAHP/AHPweb.html. With an appropriate software, all that is required is for the practitioner to form the comparison matrix for the selection criteria. When the matrix is entered into the software, the vector of priorities (criteria weightings) and the consistency index (CI) are calculated. The CI value substituted in Equation. 7 enables the consistency ratio (CR) to be calculated and compared with the threshold value of $<0 \cdot 10$ proposed by Saaty (1990). This ratio is used as a check of the consistency and usefulness of the pair-wise comparison of criteria. For example, if criterion $\mathrm{A}$ is judged to be three times as important as $\mathrm{B}$, and $\mathrm{B}$ is four times as important as $\mathrm{C}$., then it is expected that $\mathrm{A}$ will be 12 times as important as $\mathrm{C}$. If in the comparison matrix, therefore, $\mathrm{A}$ is shown to be, say, five times as important as $\mathrm{C}$, this will be an inconsistency which will be reflected in the value of the CR calculated. This is what distinguishes AHP from similar techniques.

Scoring the contractors on each criterion and calculating the total weighted score to obtain the tender performance 
index (TPI) is more straightforward and much easier using Equation 11.

The purpose of the paper was to demonstrate a simple application of AHP in contractor selection using a real-life project. Some of the criteria used may not be appropriate under the stringent laws of competition in a country such as the UK as rightly pointed out by the contributor. However, the paper has shown that we can use a combination of appropriate criteria and the AHP technique for objective and transparent competitive contractor selection. It is therefore hoped that practitioners such as the contributor and others will use the paper as a basis to advance the use of the AHP approach in contractor selection.

\section{REFERENCES}

Ciria (Construction Industry Research and Information Association) (1998) Selecting by Value. Ciria, London, UK.

Oladapo AA (2011) Multi-criteria contractor selection - a practical application of analytic hierarchy process. Proceedings of the Institution of Civil Engineers Management, Procurement and Law 164(2): 79-88. Saaty TL (1990) The Analytic Hierarchy Process - Planning, Priority Setting, Resource Allocations. RWS Publications, Pittsburgh, PA, USA. 